\title{
Analytical Performance of a Venturi-assisted Array of Micromachined UltraSonic Electrosprays (AMUSE) Coupled to Ion Trap Mass Spectrometry for the Analysis of Peptides and Proteins
}

\author{
Christina Y. Hampton ${ }^{1}$, Thomas P. Forbes ${ }^{2}$, Mark J. Varady ${ }^{2}$, J. Mark Meacham ${ }^{3}$, Andrei G. \\ Fedorov $^{2,4}$, F. Levent Degertekin ${ }^{2}$, and Facundo M. Fernández ${ }^{1,{ }^{*}}$ \\ 1 School of Chemistry and Biochemistry, Georgia Institute of Technology, Atlanta, Georgia 30332 \\ 2 George W. Woodruff School of Mechanical Engineering, Georgia Institute of Technology, Atlanta, Georgia \\ 30332
}

3 Biochemical Sciences Division, National Institute of Standards and Technology, Gaithersburg, MD 20899

4 Parker H. Petit Institute of Bioengineering and Bioscience, Georgia Institute of Technology, Atlanta, GA 30332

\begin{abstract}
The analytical characterization of a novel ion source for mass spectrometry named Array of Micromachined UltraSonic Electrosprays (AMUSE) is presented here. This is a fundamentally different type of ion generation device, consisting of three major components: 1) a piezoelectric transducer that creates ultrasonic waves at one of the resonant frequencies of the sample-filled device, 2) an array of pyramidally-shaped nozzles micromachined on a silicon wafer, and 3) a spacer which prevents contact between the array and transducer ensuring the transfer of acoustic energy to the sample. A high pressure gradient generated at the apices of the nozzle pyramids forces the periodic ejection of multiple droplet streams from the device. With this device, the processes of droplet formation and droplet charging are separated, hence, the limitations of conventional electrospraytype ion sources, including the need for high charging potentials and the addition of organic solvent to decrease surface tension can be avoided. In this work, a Venturi device is coupled with AMUSE in order to increase desolvation, droplet focusing, and signal stability. Results show that ionization of model peptides and small tuning molecules is possible with DC charging potentials of $100 \mathrm{~V}_{\mathrm{DC}}$ or less. Ionization in RF-only mode (without DC biasing) was also possible. It was observed that, when combined with AMUSE, the Venturi device provides a 10-fold gain in signal-to-noise ratio for $90 \%$ aqueous sample solutions. Further reduction in the diameter of the orifices of the micromachined arrays, led to an additional signal gain of at least 3 orders of magnitude, a 2- to 10-fold gain in the signal-to-noise ratio, and an improvement in signal stability from 47\% to 8.5\% RSD. The effectiveness of this device for the soft ionization of model proteins in aqueous media, such as cytochrome $\mathrm{C}$ was also examined, yielding spectra with an average charge state of 8.8 when analyzed with a $100 \mathrm{~V}_{\mathrm{DC}}$ charging potential. Ionization of model proteins was also possible in RF-only mode.
\end{abstract}

\section{Introduction}

Efficient conversion of dissolved neutral molecules into low-internal energy gas-phase ions is one of the most fundamental challenges in mass spectrometry (MS) ${ }^{1,2}$. Soft ionization

*Corresponding author: Facundo M. Fernández, Ph.D., Phone: 404-385-4432, Fax: 404-385-6447, Email:

facundo.fernandez@chemistry.gatech.edu. 
methods such as matrix-assisted laser desorption/ionization (MALDI3, 4 ), and electrospray ionization $\left(\mathrm{ESI}^{-7}\right)$ in microelectrospray ${ }^{8}$ or nanospray 9 formats, now routinely enable the generation of gas-phase ions from dissolved neutral molecules.

Nanospray ionization (nanoESI), one of the preferred methods for proteomic workflows, is typically conducted using pulled or tapered glass capillaries, to which charging voltages between $900 \mathrm{~V}_{\mathrm{DC}}$ and $1500 \mathrm{~V}_{\mathrm{DC}}$ are applied, resulting in sensitivities that are 10-100 times greater than that for conventional ESI ${ }^{10}$. NanoESI is particularly amenable to miniaturization, and spray nozzles with internal diameters of a few microns have been successfully fabricated with techniques normally used for the manufacturing of semiconductor microchips 11 . Microfabricated nanospray devices offer a number of advantages for mass spectrometric analysis, including reduced sample consumption and cross-contamination, improved sprayer reproducibility, high-throughput and automation capabilities, and the potential for integration with on-chip solid-phase extraction, and chromatographic or electrophoretic separations 12 , 13.

Reported miniaturized nanospray infusion devices fall into three main categories: (1) devices using fused silica capillary emitters attached to a chip ${ }^{14-21},(2)$ devices using a microchannel exiting the edge of a wafer ${ }^{22-29}$, and (3) monolithic devices using etched ESI tips $30-36$. Integrated miniaturized nanoESI devices comprising enrichment columns, reverse-phase separation channels and micromachined nanospray emitters have also been recently reported ${ }^{37-39}$. Although all of these devices have been shown to successfully generate gasphase ions from small sample volumes $(n L-\mu L)$, they still rely on the generation of a Taylor cone for liquid atomization.

One of the disadvantages of Taylor cone liquid atomization is that the high voltage required for effective ionization sets a minimum to the distance between the sprayer and other instrument components that can be used for operation without electrical discharges. This minimum distance limits the efficiency with which highly-charged nanospray droplets can be collected and transmitted into the mass spectrometer by the heated capillary interface. In addition, the Taylor cone behavior is highly influenced by the surface tension of the sprayed solution, and thus, signal stability is greatly improved by the addition of organic solvents. However, these solvents may modify the native conformation of the solutes thus distorting, to an unknown extent, the correlation between solution-phase and gas-phase conformations 40,41 . Moreover, in scenarios where analytes with largely disparate concentrations are present in the sprayed solution, the intrinsic limitation in the total current that can be supported by Taylor cone electrospray can seriously limit the dynamic range, and concomitantly, the relative peak intensities 32,42 .

In order to overcome some of the innate limitations of Taylor cone electrospray mass spectrometry, several reports on the use of acoustic liquid ejection for ESI purposes have been reported. In 1994, Banks et. al. introduced an ultrasonic electrospray approach which used a piezoelectric transducer to produce a continuous droplet stream by Rayleigh vibrational breakup of a liquid jet 43,44 . The underlying motivation for this approach was to decouple the spray formation and ionization processes, allowing the efficient and stable ionization of analytes from solutions containing little or no volatile solvents. However, the proposed ultrasonically-assisted ionization device suffered from instabilities due to temperature variations that affected the resonant frequency needed for optimum ejection. Shiea et al. also recognized the potential of ultrasonic nebulization and coupled an ultrasonic nebulizer, originally designed for inductively-coupled plasma spectrometry, to an array of 7 electrospray nozzles to which a charging voltage of $4000 \mathrm{~V}_{\mathrm{DC}}$ was applied, showing the feasibility of generating multiply charged protein ions 45 . Smith et. al. later utilized drop-on-demand technology in conjunction with ESI, with charging voltages of up to $4900 \mathrm{~V}_{\mathrm{DC}}$ to sensitively 
ionize insulin samples dissolved in 1:1 methanol/water, $1 \%$ acetic acid 46 . In this approach, a single droplet is released from the end of a capillary as a result of a rapid pressure pulsation generated by a radially-contracting piezoelectric element. Droplet bursts or continuous trains are ejected from this capillary by application of a corresponding pulse burst or sine wave to the cylindrical piezoelectric actuator surrounding the electrospray capillary. In a related experiment, Murray et. al. demonstrated the feasibility of performing MALDI MS on aerosol particles derived from discrete droplets produced using a piezoelectric dispenser ${ }^{47}$.

Here, we present our first results on the ionization of peptides and proteins from aqueous solutions containing no organic solvent by the AMUSE (Array of Micromachined UltraSonic Electrosprays) ion source. The AMUSE ion source was invented by Fedorov and Degertekin for high throughput, multiplexed $\mathrm{MS}^{48}$ and first demonstrated on a MS system jointly by the Fedorov, Degertekin, and Fernandez groups ${ }^{49}$. AMUSE intends to overcome the limitations of conventional nanoESI arrays based on Taylor cone liquid atomization by acoustically driving the ejection of droplets, thus offering the potential for high-throughput, on-demand, multiplexed and inexpensive mass spectrometric analysis with minimum sample consumption. In this paper we show that by coupling the AMUSE ion source to an ion trap mass spectrometer via a Venturi droplet focusing device ${ }^{50-52}$, the sensitive and stable ionization of proteins and peptides at picomole to femtomole levels is possible without incorporating an organic solvent in the analyte mixture. Furthermore, we demonstrate that ionization can be achieved at very low charging potentials (50-350 $\mathrm{V}_{\mathrm{DC}}$ ), or even in RF-only mode.

\section{Experimental}

\section{Materials}

Reserpine (Sigma, St. Louis, MI), horse heart cytochrome C, (Acros Organics, Geel, Belgium), and leucine enkephalin (American Peptide, Sunnyvale, CA) were purchased and used without additional purification. Methanol (HPLC grade) was purchased from Fisher (Hampton, NH). Working solutions of each compound $(1-10 \mu \mathrm{M})$ were prepared in nanopure water $(18 \mathrm{M} \Omega$ $\mathrm{cm}^{-1}$, Barnstead International, Dubuque, Iowa) containing $0.1 \%(\mathrm{v} / \mathrm{v})$ glacial acetic acid (Sigma-Aldrich, St. Louis, MI). Except for initial exploratory experiments with reserpine, no organic solvent was added to the working solutions. The sample solution was delivered to the analyte reservoir at flow rates ranging from 30 to $100 \mu \mathrm{L} \mathrm{min}^{-1}$, equivalent to $75-250 \mathrm{~nL}$ $\min ^{-1}$ per nozzle.

\section{Nozzle array fabrication}

Two types of nozzle arrays were used: a first generation $20 \times 20$ array of 5- $\mu$ m nozzles, and a second generation $20 \times 20$ array of $3-\mu \mathrm{m}$ nozzles. Fabrication of the first ${ }^{49}$ and second generation arrays ${ }^{53}$ has been described in detail elsewhere.

\section{Acoustic micromachined array assembly, ion source setup and operation}

The AMUSE 54,55 assembly is shown in Figure 1(A). This assembly consists of five main components. (1) A 2-mm thick piezoelectric transducer (American Piezo Ceramics Inc., Mackeyville, PA) coated on both sides with gold electrodes served as the base of the AMUSE assembly. (2) A 730- $\mu$ m thick spacer made of Kapton tape (DuPont, Wilmington, DE) which was placed on top of the piezo, and used to define the thickness of the $105-\mu \mathrm{L}$ analyte reservoir formed by positioning a 790- $\mu \mathrm{m}$ thick silicone insert (McMaster-Carr, Atlanta, GA) in the center of the Kapton spacer. One edge of the silicone insert was pierced by a 3-cm long piece of 255- $\mu \mathrm{m}$ i.d. 510- $\mu \mathrm{m}$ o.d. PEEK tubing (Upchurch Scientific, Oak Harbor, WA). This piece of tubing was connected to the external sample flow circuit via a 1-mm wide slit cut into one side of the Kapton spacer. (3) The micromachined nozzle array $(24 \times 24-\mathrm{mm})$ containing 400 pyramidally-shaped 125 -nL cavities each capped with a 3 - or 5- $\mu$ m diameter nozzle, was placed 
on top of the spacer/insert assembly sealing the reservoir. This part of the assembly was then topped by (4) a second silicone spacer (McMaster-Carr, Atlanta, GA) used to protect the array from accidental damage during the sealing process and (5) a 1-mm thick brass seal (McMasterCarr, Atlanta, GA) that provided a rigid surface for compression by a pair of spring-loaded clamps (not shown). Sample was introduced into the reservoir by connecting the PEEK tube protruding from the silicone insert to a piece of 508- $\mu \mathrm{m}$ i.d. PEEK tubing (Upchurch Scientific, Oak Harbor, WA), which was attached to a liquid handling pump (Valco Instruments Co., VICI M6, Houston, TX.).

Figure 1(B) shows the Venturi-assisted AMUSE-MS setup. Lead wires were soldered onto the inner and outer gold electrodes on the piezoelectric transducer, and connected to a DC power supply (Stanford Research Systems Inc., Sunnyvale, CA), and an RF amplifier (T\&C Power Conversion Inc., Rochester, NY), respectively. The DC voltage power supply was used to apply charging voltages of $0-500 \mathrm{~V}_{\mathrm{DC}}$ to the inner electrode. Operation in RF-only mode was achieved by removing the connections to the DC power supply, and connecting the ground lead of the RF amplifier directly to the front side of the piezo which was in contact with the analyte reservoir. Electrical signals in the frequency range of $900 \mathrm{kHz}-1 \mathrm{MHz}$ with 0.220 $0.300 \mathrm{~V}_{\mathrm{PP}}$ amplitude produced by a function generator (Stanford Research Systems Inc., Sunnyvale, CA) were used to drive the transducer exciting the cavity resonances. The amplified RF potential was applied to the outer gold electrode of the piezoelectric transducer and was monitored using an oscilloscope (Tektronix, Beaverton, OR). The RF potential applied to the piezoelectric transducer generates a high pressure gradient at the apex of each nozzle due to wave focusing of the standing acoustic pressure waves produced within the device cavity forcing the ejection of a droplet stream. The droplet size is mainly determined by the nozzle orifice size. Under the operating conditions used in this study, droplets approximately have an average diameter that is $1-2 \mu \mathrm{m}$ larger than the orifice diameter ${ }^{53}$.

Prior to mass spectrometric experiments, the AMUSE was placed approximately $2 \mathrm{~mm}$ from the inlet of a stainless steel Venturi air amplifier (HMC Brauer Co., Milton Keynes, England) operated with nitrogen at rates of $0-17 \mathrm{~L} \mathrm{~min}^{-1}$. The nitrogen flow rate was controlled using a differential pressure flowmeter (Bel-Art, Pequannock, NJ). The nitrogen gas was used at room temperature except for experiments with proteins, where the nitrogen was heated using an inline air circulation heater (Omega, Stamford, CT) and a temperature controller (Eppendorf, Hamburg, Germany).

\section{Mass Spectrometry}

Initial experiments with 5- $\mu \mathrm{m}$ AMUSE devices were performed with a linear ion trap (LiT) mass spectrometer (LTQ, ThermoFinnigan, Waltham, MA). Experiments with 3- $\mu$ m devices were performed with a quadrupolar ion trap (QiT) mass spectrometer (LCQ Deca XP+, ThermoFinnigan, Waltham, MA). In both cases, the standard electrospray ion source was removed, and the Venturi air amplifier was positioned directly in front of the heated capillary inlet of the mass spectrometer. For LiT experiments, the following mass spectrometer settings were used: $13-34 \mathrm{~V}_{\mathrm{DC}}$ inlet capillary voltage, $275^{\circ} \mathrm{C}$ capillary temperature, $100-200 \mathrm{~ms}$ trapping time. For QiT experiments, the following settings were used: $8-23 \mathrm{~V}_{\mathrm{DC}}$ inlet capillary voltage, $300{ }^{\circ} \mathrm{C}$ capillary temperature, $100 \mathrm{~ms}$ trapping time. Settings were optimized for the respective protonated molecules using the auto tune function of the mass spectrometer. Prior to mass spectrometric analysis, the liquid reservoir of the AMUSE device was primed with the sample to be analyzed, and after stable liquid ejection was visually verified, the Venturi air amplifier was turned on, and mass spectral data was acquired in positive ion mode.

Conventional ESI and nanoESI experiments were performed on the QiT with the standard commercial ion sources provided by the mass spectrometer manufacturer (ThermoFinnigan, Waltham, MA), at a flow rate of $10 \mu \mathrm{L} \mathrm{min}^{-1}$ and $4.5 \mathrm{kV}_{\mathrm{DC}}$ for ESI, and $0.8 \mu \mathrm{L} \mathrm{min}{ }^{-1}$, and 2.5 
$\mathrm{kV}_{\mathrm{DC}}$ for nanoESI. Nanospray emitter tips (30- $\mu \mathrm{m}$ i.d.) were obtained from New Objective (Woburn, MA).

\section{Results and Discussion}

\section{Effect on Signal Intensity and Stability Due to Incorporation of Venturi Device}

Our initial, proof-of-principle experiments performed using the AMUSE on a time-of-flight (TOF) mass spectrometer demonstrated the potential of this device as a viable ion source ${ }^{49}$. However, inconsistent droplet collection and limited desolvation hindered further characterization of the AMUSE ion source in that particular instrumental configuration. One of the problems was that the particular TOF mass spectrometer used in our early experiments is furnished with a small heated orifice for accepting ions into the first differentially pumped region of the atmospheric pressure interface, not a heated capillary. Desolvation at this orifice is limited when the original ESI ion source is replaced with the AMUSE device, as in this particular instrument the heated element is located in the electrospray needle housing, which was removed for AMUSE experiments. This difficulty was circumvented by attaching the AMUSE ion source to an ion trap mass spectrometer which uses a heated capillary as the first element of the atmospheric pressure interface. In addition, visualization studies of droplet ejection from the AMUSE device showed that the ejection process produces droplets with very high velocities $\left(10-20 \mathrm{~m} \mathrm{~s}^{-1}\right)$ which decelerate very rapidly due to Stokes drag ${ }^{54}$. In terms of coupling this device to a mass spectrometer, this behavior translated into unstable focusing of the AMUSE-generated droplets onto the mass spectrometer inlet. In order to improve droplet transport a Venturi industrial air amplifier was incorporated between the AMUSE ion source and the mass spectrometer inlet. Zhou, et. al. have reported that the incorporation of a nonbiased Venturi device can lead to a 5 -fold increase in the $[\mathrm{M}+\mathrm{H}]^{+}$ion intensity of electrosprayed reserpine relative to signal obtained without the Venturi device, due to improved focusing of the highly-charged diverging nanodroplet cloud formed during ESI ${ }^{50}$. Therefore, we speculated that the coupling of such a device to the AMUSE would provide the necessary droplet stream stabilization, focusing and desolvation to achieve more stable ionization of polar biomolecules.

Figure 2 shows the mass spectra obtained for a reserpine solution ionized by the application of $100 \mathrm{~V}_{\mathrm{DC}}$ charging potential to a 5- $\mu \mathrm{m}$ AMUSE device with and without Venturi-assisted droplet desolvation. As can be seen in the figure, the signal intensity of the protonated molecule $(\mathrm{m} / \mathrm{z}=609.2)$ obtained using the Venturi device was increased 10-fold with respect to that obtained without it. A similar gain in signal-to-noise ratio was observed. This gain is a result of both the improved stabilization and transmission of the ejected droplet stream into the heated capillary inlet, and of the aforementioned desolvation effect afforded by the Venturi air amplifier.

The greater sensitivity gain obtained here (10x) compared to that reported by Zhou, et. al. in the absence of a potential applied to the air amplifier $(5 x)$, can most likely be attributed to the improved sampling of the multiple droplet streams when the AMUSE is used in the Venturi mode. Figure S-1 shows the total ion trace obtained for the reserpine mass spectrum obtained when the gas flow to the Venturi device is shut off and when the device is operated at a flow rate of $9.3 \mathrm{~L} \mathrm{~min}^{-1}$. As can be seen in the upper trace, unstable droplet collection causes the signal to oscillate precipitously throughout the analysis, leading to a large instability in the detected signal ( $\% \mathrm{RSD}=202 \%)$. Incorporation of a Venturi device increased the overall stability of the method to $47 \%$ RSD, but sensitivity was still lower than expected, most likely due to the relatively larger initial droplet diameter produced by the $5-\mu \mathrm{m}$ nozzle array. 


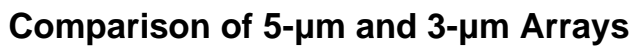

The improvement in absolute signal intensity and signal-to-noise ratio for both reserpine and leucine enkephalin, using a $3-\mu \mathrm{m}$ nozzle device relative to that obtained using a $5-\mu \mathrm{m}$ nozzle device is shown in Figure 3. All spectra were obtained from solutions prepared in ultrapure water with $0.1 \%$ acetic acid added. The droplet ejection and Venturi focusing conditions were optimized for each device type. An applied DC potential of $100 \mathrm{~V}_{\mathrm{DC}}$ was used in all cases, which represents a 20 to 45 -fold decrease in charging voltage if compared to traditional electrospray operation. The ion intensity of the $[\mathrm{M}+\mathrm{H}]^{+}$peak of reserpine $(\mathrm{m} / \mathrm{z}=609.2)$ using the 3- $\mu \mathrm{m}$ device was more than 30,000 times greater than that of the 5- $\mu \mathrm{m}$ device, while the overall signal-to-noise ratio was increased from 172 for the $5-\mu \mathrm{m}$ device to 345 for the $3-\mu \mathrm{m}$ device. Improvements were also observed for the ionization of leucine enkephalin, where the absolute signal gain was greater than 3,000, while the signal-to-noise ratio showed a 10-fold increase. When examining these improvements, it must also be considered that LiT MS detection was used to measure ions produced by the 5- $\mu \mathrm{m}$ device while QiT MS detection was used to measure ions produced by the $3-\mu \mathrm{m}$ devices. As LiT detection is more sensitive than QiT detection due to a larger ion trapping capacity, these results suggest that had the experiments using the 3- $\mu \mathrm{m}$ device been performed on the LiT, the improvement in response could have been even greater.

The relatively abundant peaks of the dimer $\left([2 \mathrm{M}+\mathrm{H}]^{+} ; m / z=1111.1\right)$ and trimer $\left([3 \mathrm{M}+\mathrm{H}]^{+}\right.$; $m / z=1666.1)$ species of leucine enkephalin present in spectra obtained using the AMUSE are generally not observed in mass spectra obtained with conventional ESI (Figure S-2). In the AMUSE, droplets are produced with no use of an electric field, rather than being formed as a result of the Taylor cone electrohydrodynamic instability and vigorous Coulombic explosions as is typical in ESI. The lower DC potential applied to the droplets produced by the AMUSE is still capable of inducing droplet charging by electrophoretic charge separation or electrochemical reactions. This fundamentally different ionization mechanism possibly favors ion formation by evaporation of solvent from the charged droplets rather than ion evaporation, thus, favoring the stabilization of non-covalent interactions and possibly producing softer ionization than ESI. This suggests that in the future, AMUSE ionization may find applicability for the ionization of labile species such as non-covalent protein complexes.

Because in the prototype devices evaluated here, individual liquid ejection from each reservoir is not yet implemented, it is not possible to estimate the number of droplet streams being sampled by the inlet capillary, and thus, detection limits can only be estimated, but not accurately calculated, until development of a fully multiplexed AMUSE device which enables the ejection from a single nozzle is accomplished. Detection limits were 10 picomoles reserpine for the $5-\mu \mathrm{m}$ arrays and 3 picomoles reserpine for the 3- $\mu \mathrm{m}$ arrays. In terms of analyte amount ejected per nozzle, calculated detection limits were 100 femtomoles reserpine/nozzle for 5$\mu \mathrm{m}$ devices and 15 femtomoles reserpine/nozzle for 3- $\mu \mathrm{m}$ devices. These detection limits were determined by calculating the number of analyte moles ejected over 1.2 seconds, the minimum time that can be averaged using the instrument's software, and dividing this value by the number of nozzles ejecting during spectral collection. The number of ejecting nozzles was visually estimated, and typically was $10 \%$ for $5-\mu \mathrm{m}$ arrays and $25 \%$ for $3-\mu \mathrm{m}$ arrays.

The air amplifier nitrogen flow rate was found to have a marked effect on the intensity of the $[\mathrm{M}+\mathrm{H}]^{+}(\mathrm{m} / \mathrm{z}=556.1)$ leucine enkephalin ion. The results shown in Figure S-3 suggest that the optimum inlet flow rate of nitrogen is between $7-10 \mathrm{~L} \mathrm{~min}^{-1}$. These flow rates produce a 10 -fold increase in the outlet flow rate according to the manufacturer's specifications ${ }^{56}$. The use of 3- $\mu \mathrm{m}$ arrays in combination with the Venturi air amplifier not only increased sensitivity, but also increased the stability of the ion signal, as seen in Figure S-4, which shows the total and extracted ion traces for the ionization of a $5 \mu \mathrm{M}$ solution of leucine enkephalin. The $3-\mu \mathrm{m}$ devices were shown to be stable ( $8.5 \%$ RSD) for up to 30 minutes at the liquid flow rates 
assayed here. Using these optimized conditions, the effect of changing the bias voltage used for droplet charging during ionization was explored.

\section{Effect of Varying the Applied DC Potential}

Ionization by the AMUSE is accomplished in a totally different way than in conventional electrospray, as droplet formation is decoupled from droplet charging. The decoupling of these two processes enables the stable ionization of peptides and small molecules dissolved in acidified aqueous solutions at potentials of a few hundred volts. This results in safer operation of the ion source, and the possibility of placing the AMUSE assembly surface in close proximity to the Venturi air amplifier inlet without generating electrical discharges.

To further explore the dependence of AMUSE ion generation on the applied DC charging potential, a series of spectra were collected for a $1 \mu \mathrm{M}$ leucine enkephalin solution at increasing DC bias. Figure 4 shows the intensity of the protonated molecule of leucine enkephalin (top) as well as the corresponding signal-to-noise ratio (bottom) as a function of the applied DC potential. As can be seen in this figure, it is possible to obtain ionization using a range of potentials, or even without any DC potential at all (RF-only mode). The absolute intensity appears to be at a maximum at approximately $350 \mathrm{~V}_{\mathrm{DC}}$ while the corresponding signal-to-noise ratio appears to increase throughout the entire range of applied DC potentials, with a local maximum at approximately $280 \mathrm{~V}_{\mathrm{DC}}$. For charging voltages of $350 \mathrm{~V}_{\mathrm{DC}}$ and higher, significant liquid buildup on the device surface was observed, which hindered droplet ejection from some nozzles or nozzle clusters. This phenomenon was accompanied by a concomitant reduction in signal intensity. One possible explanation to this phenomenon is that the negatively-charged oxygen atoms on the tungsten array surface attract the positively-charged liquid meniscus produced at the onset of the droplet ejection event ${ }^{57}$. Higher potentials cause higher surface droplet charging, and thus could favor wetting by the tungsten surface. More experiments are now underway to understand this phenomenon. Covalent chemical modification of the array surface via silane chemistry, and the development of next generation prototypes with hydrophobic polymer layers on their outer surface, are also being investigated to further minimize this effect.

The devices with smaller nozzle orifice diameter appeared to produce the most stable signal with no DC potential applied at all. Figure 5 shows the mass spectrum (top) and total ion trace (bottom) obtained for a $1 \mu \mathrm{M}$ leucine enkephalin solution when the AMUSE was operated in RF-only ionization mode. The signal-to-noise ratio of the $[\mathrm{M}+\mathrm{H}]^{+}$peak obtained using this mode was 41 , while the total ion trace showed a $2.6 \%$ RSD over the course of one minute. In this ionization mode, the RF voltage signal induces periodic charging on the electrode facing the analyte solution. With amplification, the amplitude of the RF signal needed for ejection approaches $50-150 \mathrm{~V}_{\mathrm{PP}}$, so the period-averaged positive potential seen by the sample is $+(50-$ 150) $\mathrm{V}_{\mathrm{PP}} /(2 \pi)=(8-24) \mathrm{V}$, sufficient for droplet charging, as observed from experiments with time-invariant DC potentials. So, in other words, we speculate that droplet charging still occurs even though the DC bias is not applied to the electrode. It must be noted, however, that this mode is less efficient, as the analyte "sees" the positive potential only half of the time, thus leading to the lower signal-to-noise ratio observed.

\section{AMUSE lonization of Proteins}

To further explore the usefulness of the AMUSE as a viable ion source for biological mass spectrometry, the feasibility of ionizing model proteins from aqueous media was investigated. Initial experiments with a $4 \mu \mathrm{M}$ cytochrome $\mathrm{C}$ solution in $0.1 \%$ acetic acid (pH 3.2) yielded spectra with low signal-to-noise ratio, as shown in Figure 6A. This could most likely be attributed to incomplete protein ion desolvation, as proteins are more difficult to desolvate due to their larger number of hydrogen-bonding sites. To improve desolvation, a heater was used 
to increase the temperature of the nitrogen flowing through the Venturi device. Figure $6 \mathrm{~B}$ shows the spectrum obtained for the same solution and identical conditions to the spectrum in $6 \mathrm{~A}$ but with the addition of nitrogen heated to $40{ }^{\circ} \mathrm{C}$, as measured at the outlet of the Venturi air amplifier. The use of heated nitrogen caused a slight narrowing of the charge state distribution generating a spectrum with an average charge state of 8.8 , and a signal-to-noise ratio of 55 for the +8 charge state as compared to an average charge state of 10 and signal-to-noise ratio of 7 for the +11 charge state in the spectrum obtained using ambient temperature nitrogen.

Additional experiments demonstrated that it was also possible to ionize cytochrome C in RFonly mode, as shown in Figure S-5, which presented a signal-to-noise ratio of 21 for the +8 charge state, and an almost identical average charge state of 8.9, when compared to the spectrum shown in Figure 6B.

Figure S-6 shows the standard nanospray mass spectrum obtained for the exact same solution previously ionized with the AMUSE. As can be seen in the figure, the charge state distribution in this case was quite narrow, yielding an average charge state of 9.24, which is higher than what was obtained using the AMUSE. This charge state distribution is consistent with previous reports for cytochrome $\mathrm{C}$ solutions at a $\mathrm{pH}$ higher than 3 , containing no organic solvent ${ }^{58}$. The slight decrease of the average charge state observed using the AMUSE relative to that using nanospray ionization could be attributed to the gentler ionization provided by the Venturi device as reported by Yang, et. al. ${ }^{52}$, and possibly also to the AMUSE ionization process itself. By comparison, ESI and nanoESI using the more standard 1:1 methanol:water with $0.1 \%$ acetic acid solvent mixture ( $\mathrm{pH} 4.0$ ) and under the exact same instrumental conditions produced spectra having wide charge state distributions and an average charge state of 16 (Figure S-7). On-going work is being conducted to determine the degree to which ionization by the AMUSE preserves protein solution-phase conformation, and to quantify the overall "softness" of AMUSE ionization.

\section{Conclusions}

The results presented here show that the sensitive and stable ionization of proteins and peptides at picomole to femtomole levels per nozzle is possible without the addition of organic solvent into the analyte mixture and using very low, or no, applied charging potential, thus opening new avenues for the production of gas-phase ions for biological mass spectrometry. Incorporation of the Venturi device provided a 10-fold gain in both the signal and signal-tonoise ratio for a reserpine spectrum obtained using a $5-\mu \mathrm{m}$ array as well as a 4 -fold reduction in the relative standard deviation of the corresponding total ion trace indicating an overall increase in sensitivity and stability as a result of the improved droplet desolvation and focusing efficiency of this setup. Modifications to the fabrication protocol to generate $3-\mu \mathrm{m}$ arrays led to an increase in sensitivity by at least 3 orders of magnitude and a 2 to 10 -fold increase in the signal-to-noise ratio. The stability of the signal produced by the AMUSE was also much improved using the new arrays yielding a relative standard deviation of $11.3 \%$ in the intensity as measured over 30 minutes while that measured over 1 minute was generally $2-3 \%$.

\section{Supplementary Material}

Refer to Web version on PubMed Central for supplementary material.

\section{Acknowledgements}

FMF gratefully acknowledges the initial financial support received from the American Society for Mass Spectrometry as a Research Award, sponsored by Applied BioSystems and MDS Sciex. CYH acknowledges partial support from the Molecular Biophysics Training Program at the Georgia Institute of Technology. We also thank Prof. David Muddiman for stimulating discussions as well as Dr. de Jesus and Dr. Charlene Bayer for the use of the linear ion trap mass spectrometer. This publication was made possible by Grant Number RR021474-01A1 from the National Center 
for Research Resources (NCRR), a component of the National Institutes of Health (NIH). Its contents are solely the responsibility of the authors and do not necessarily represent the official views of NCRR or NIH.

\section{References}

1. Busch KL, Cooks RG. Science 1982;218:247-254. [PubMed: 17838611]

2. Vestal ML. Chem Rev 2001;101:361-375. [PubMed: 11712251]

3. Tanaka K, Waki H, Ido Y, Akita S, Yoshida Y, Yoshida T. Rapid Commun Mass Spectrom 1988;2:151153.

4. Karas M, Hillenkamp F. Anal Chem 1988;60:2299-2301. [PubMed: 3239801]

5. Dole M, Mack LL, Hines RL, Mobley RC, Ferguson LD, Alice MB. J Chem Phys 1968;49:2240-2249.

6. Whitehouse CM, Dreyer RN, Yamashita M, Fenn JB. Anal Chem 1985;57:675-679. [PubMed: 2581476]

7. Fenn JB, Mann M, Meng CK, Wong SF, Whitehouse CM. Science 1989;246:64-71. [PubMed: 2675315]

8. Emmett MR, Caprioli RM. J Am Soc Mass Spectrom 1994;5:605-613.

9. Wilm M, Mann M. Anal Chem 1996;68:1-8. [PubMed: 8779426]

10. Wilm M, Shevchenko A, Houthaeve T, Breit S, Schweigerer L, Fotsis T, Mann M. Nature 1996;379:466-469. [PubMed: 8559255]

11. Wood TD, Moy MA, Dolan AR, Bigwarfe PM, White TP, Smith DR, Higbee DJ. Applied Spectroscopy Reviews 2003;38:187-244.

12. Limbach PA, Meng ZJ. Analyst 2002;127:693-700. [PubMed: 12146896]

13. Lazar IM, Grym J, Foret F. Mass Spectrom Rev 2006;25:573-594. [PubMed: 16508917]

14. Bings NC, Wang C, Skinner CD, Colyer CL, Thibault P, Harrison DJ. Anal Chem 1999;1999

15. Li J, Thibault P, Bings NH, Skinner CD, Wang C, Colyer C, Harrison J. Anal Chem 1999;71:30363045. [PubMed: 10450153]

16. Zhang B, Liu H, Karger BL, Foret F. Anal Chem 1999;71:3258-3264. [PubMed: 10450166]

17. Li JJ, Kelly JF, Chemushevich I, Harrison DJ, Thibault P. Anal Chem 2000;72:599-609. [PubMed: 10695148]

18. Meng ZJ, Qi SZ, Soper SA, Limbach PA. Anal Chem 2001;73:1286-1291. [PubMed: 11305664]

19. Zhang B, Foret F, Karger B. Anal Chem 2001;73:2675-2681. [PubMed: 11403316]

20. Lazar IM, Ramsey RS, Ramsey JM. Anal Chem 2001;73:1733-1739. [PubMed: 11338586]

21. Ivanov A, Zang L, Karger BL. Anal Chem 2003;75:5306-5316. [PubMed: 14710807]

22. Ramsey RS, Ramsey JM. Anal Chem 1997;69:1174-1178.

23. Xue Q, Foret F, Dunayevskiy YM, Zavracky PM, McGruer NE, Karger BL. Anal Chem 1997;69:426430. [PubMed: 9030055]

24. Le Gac S, Arscott S, Cren-Olive C, Rolando C. J Mass Spectrom 2003;38:1259-1264. [PubMed: 14696205]

25. Yang Y, Kameoka J, Wachs T, Henion JD, Craighead HG. Anal Chem 2004;76:2568-2574. [PubMed: 15117199]

26. Le Gac S, Rolando C, Arscott S. J Am Soc Mass Spectrom 2006;17:75-80. [PubMed: 16352441]

27. Dayon L, Abonnenc M, Prudent M, Lion N, Girault HH. J Mass Spectrom 2006;41:1484-1490. [PubMed: 17083086]

28. Bedair MF, Oleschuk RD. Anal Chem 2006;78:1130-1138. [PubMed: 16478104]

29. Kim W, Guo M, Yang P, Wang D. Anal Chem. 2007Articles ASAP, April 2007

30. Schultz GA, Corso TN, Prosser SJ, Zhang S. Anal Chem 2000;72:4058-4063. [PubMed: 10994965]

31. Licklider L, Wang XQ, Desai A, Tai YC, Lee TD. Anal Chem 2000;72:367-375. [PubMed: 10658332]

32. Tang KQ, Lin YH, Matson DW, Kim T, Smith RD. Anal Chem 2001;73:1658-1663. [PubMed: 11338576]

33. Zhang S, Van Pelt CK, Henion JD. Electrophoresis 2003;24:3620-3632. [PubMed: 14613186] 
34. Sjodahl J, Melin J, Griss P, Emmer A, Stemme G, Roeraade J. Rapid Commun Mass Spectrom 2003;17:337-341. [PubMed: 12569444]

35. Corkery LJ, Pang H, Schneider BB, Covey TR, Siu KWM. J Am Soc Mass Spectrom 2005;16:363369. [PubMed: 15734329]

36. Zamfir AD, Lion N, Vukelic Z, Bindila L, Rossier J, Girault HH, Peter-Katalinic J. Lab Chip 2005;5:298-307. [PubMed: 15726206]

37. Fortier MH, Bonneil E, Goodley P, Thibault P. Anal Chem 2005;77:1631-1640. [PubMed: 15762566]

38. Yin NF, Killeen K, Brennen R, Sobek D, Werlich M, van de Goor TV. Anal Chem 2005;77:527533. [PubMed: 15649049]

39. Ghitun M, Bonneil E, Fortier MH, Yin HF, Killeen K, Thibault P. J Sep Sci 2006;29:1539-1549. [PubMed: 16922269]

40. Chowdhury SK, Chait BT. Anal Chem 1991;63:1660-1664. [PubMed: 1952089]

41. Chowdhury SK, Katta V, Chait BT. J Am Chem Soc 1990;112:9012-9013.

42. Tang K, Page JS, Smith RD. J Am Soc Mass Spectrom 2004;15:1416-1423. [PubMed: 15465354]

43. Banks JF, Quinn JP, Whitehouse CM. Anal Chem 1994;66:3688-3695. [PubMed: 7802256]

44. Banks JF Jr, Shen S, Whitehouse CM, Fenn JB. Anal Chem 1994;66:406-414. [PubMed: 8135377]

45. Shiea J, Chang DY, Lin CH, Jiang SJ. Anal Chem 2001;73:4983-4987. [PubMed: 11681476]

46. Berggren WT, Westphall MS, Smith LM. Anal Chem 2002;74:3443-3448. [PubMed: 12139052]

47. He L, Murray KK. J Mass Spectrom 1999;34:909-914. [PubMed: 10491586]

48. Fedorov, AG.; Degertekin, FL. Electrospray Systems and Methods. 7,208,727. Apr 24. 2007 issued

49. Aderogba S, Meacham JM, Degertekin FL, Fedorov AG, Fernández FM. Appl Phys Lett 2005;86:203110/203111-203110/203113.

50. Zhou L, Yue B, Dearden DV, Lee ED, Rockwood AL, Lee ML. Anal Chem 2003;75:5978-5983. [PubMed: 14588040]

51. Hawkridge AM, Zhou L, Lee ML, Muddiman DC. Anal Chem 2004;76:4118-4122. [PubMed: 15253651]

52. Yang P, Cooks RG, Ouyang Z, Hawkridge AM, Muddiman DC. Anal Chem 2005;77:6174-6183. [PubMed: 16194076]

53. Meacham, JM. PhD Thesis. Woodruff School of Mechanical Engineering, Georgia Institute of Technology; Atlanta: 2006. A Micromachined Ultrasonic Droplet Generator: Design, Fabrication, Visualization, and Modeling.

54. Meacham J, Varady M, Degertekin F, Fedorov A. Phys Fluids 2005;17:100605-100601100605-100608.

55. Meacham JM, Ejimofor C, Kumar S, Degertekin FL, Fedorov AG. Rev Sci Instrum 2004;75:13471352.

56. Brauer Airmovers. http://www.brauer.co.uk/php/airmoverindex.php?csvfile=airmoverindex.csv\&indexprimary=airmover\&indextitle=Airmove

57. Graham JF, Griffiths K, Kovar M, Norton PR, Ogini F, Warren OL. Journal of Vacuum Science and Technology A 1999;17:2240-2245.

58. Grandori R. Protein Sci 2001;11:453-458. [PubMed: 11847268] 
(A)

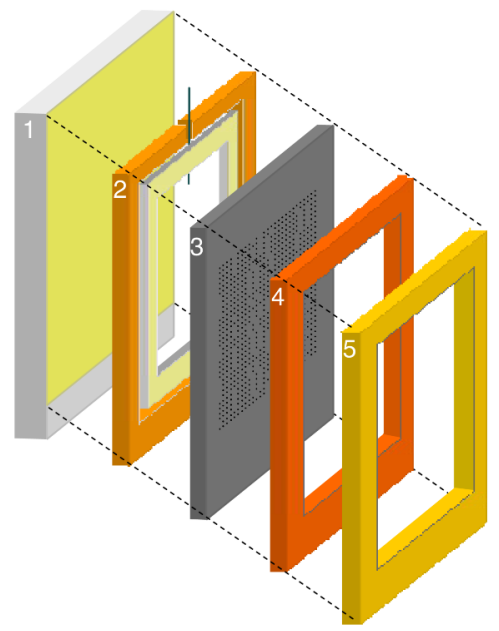

(B)

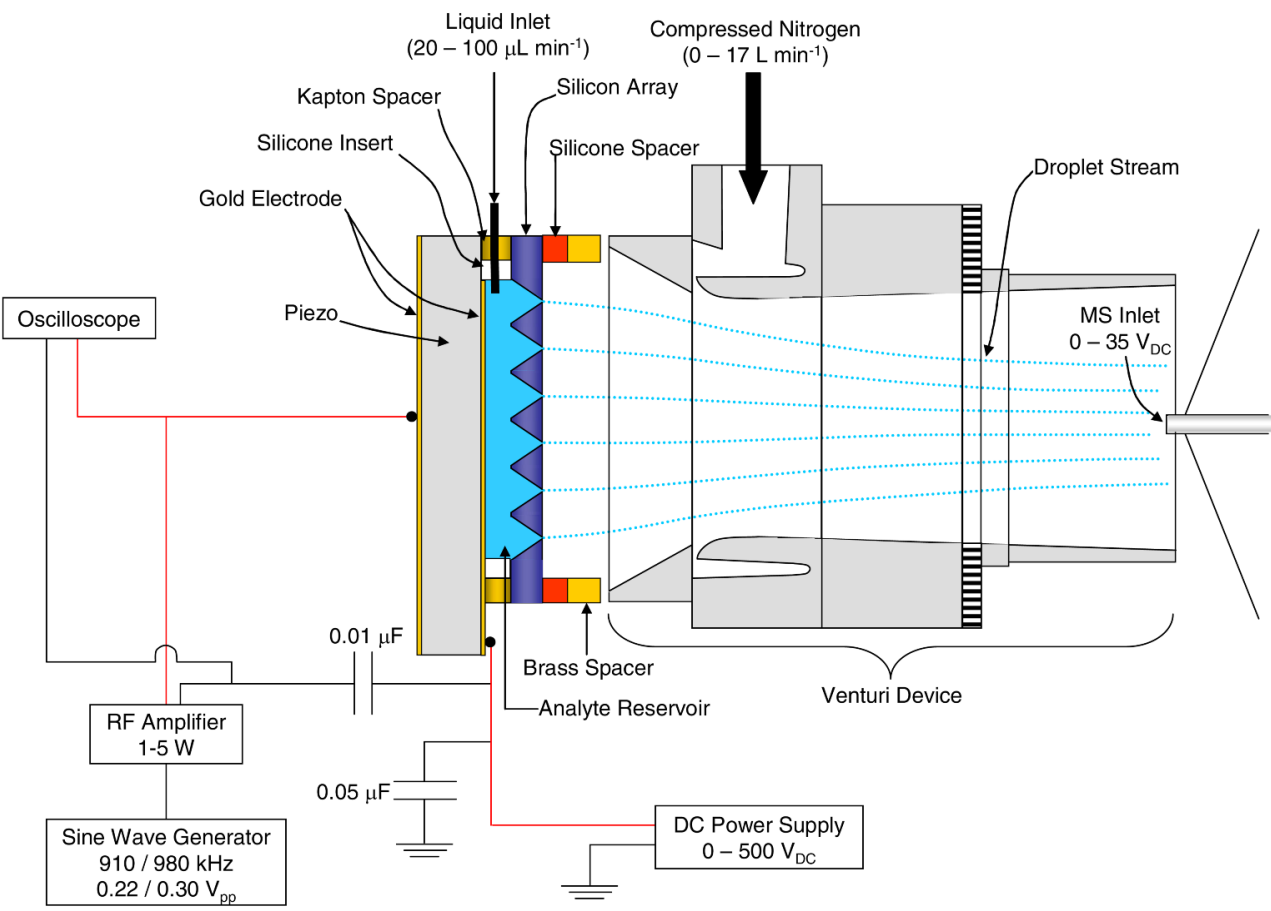

Figure 1.

(A) AMUSE device consisting of (1) gold-coated piezoelectric transducer, (2) Kapton spacer with silicone insert, (3) AMUSE chip, (4) silicone spacer, and (5) brass spacer. Fig. 1 (B) shows the fully-assembled Venturi-assisted AMUSE-MS setup. 


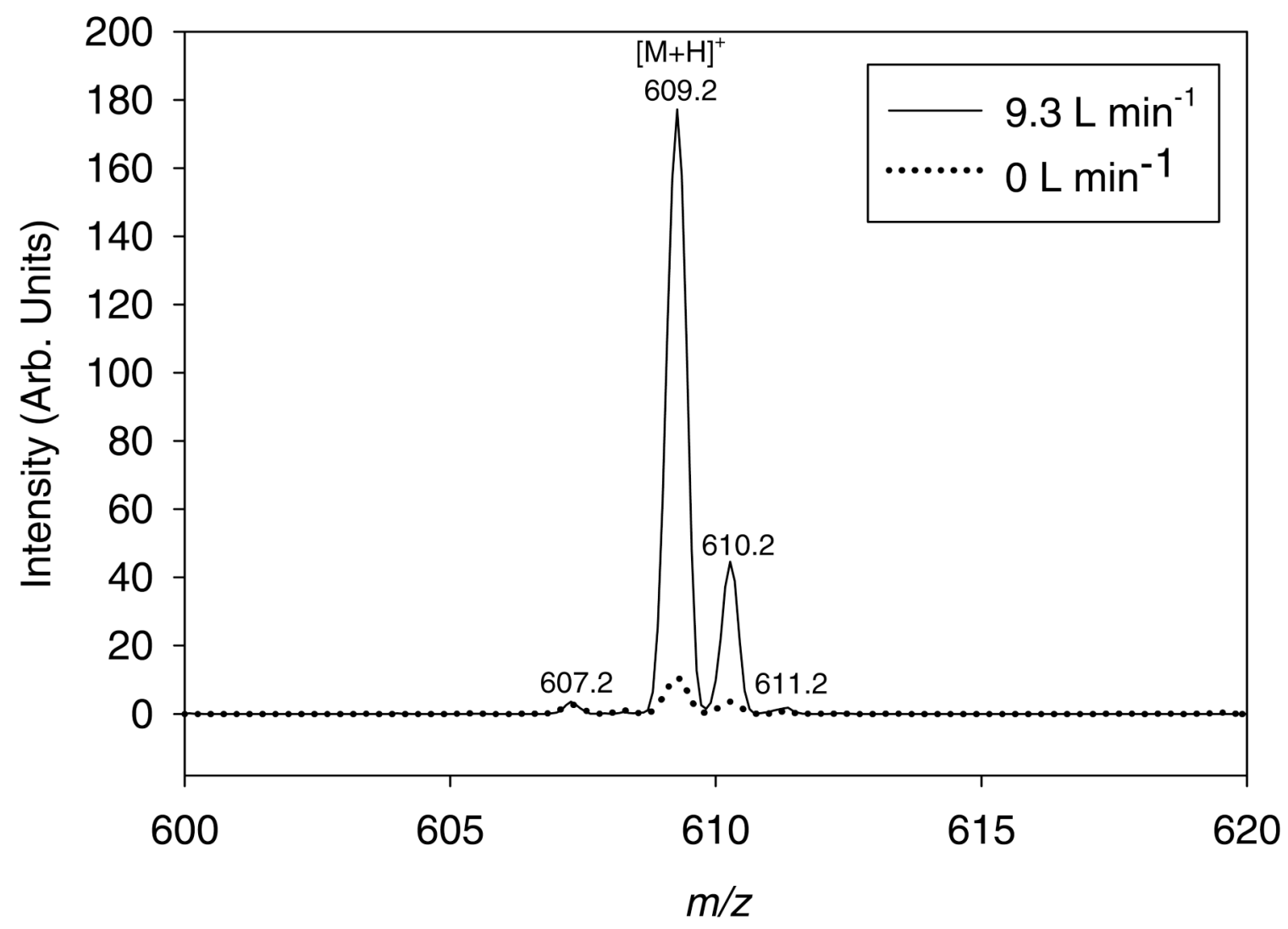

Figure 2.

Mass spectra for $\sim 4$ pmols reserpine nozzle ${ }^{-1}$ ionized by a 400 -nozzle AMUSE chip (5- $\mu$ m apertures), with $\left(9.3 \mathrm{~L} \mathrm{~min}^{-1}\right)$ or without $\left(0 \mathrm{~L} \mathrm{~min}^{-1}\right)$ Venturi-assisted droplet desolvation and focusing. The solvent used in both cases was 10:89.9:0.1 (v:v:v) methanol:water:glacial acetic

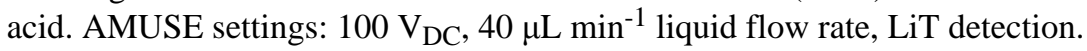




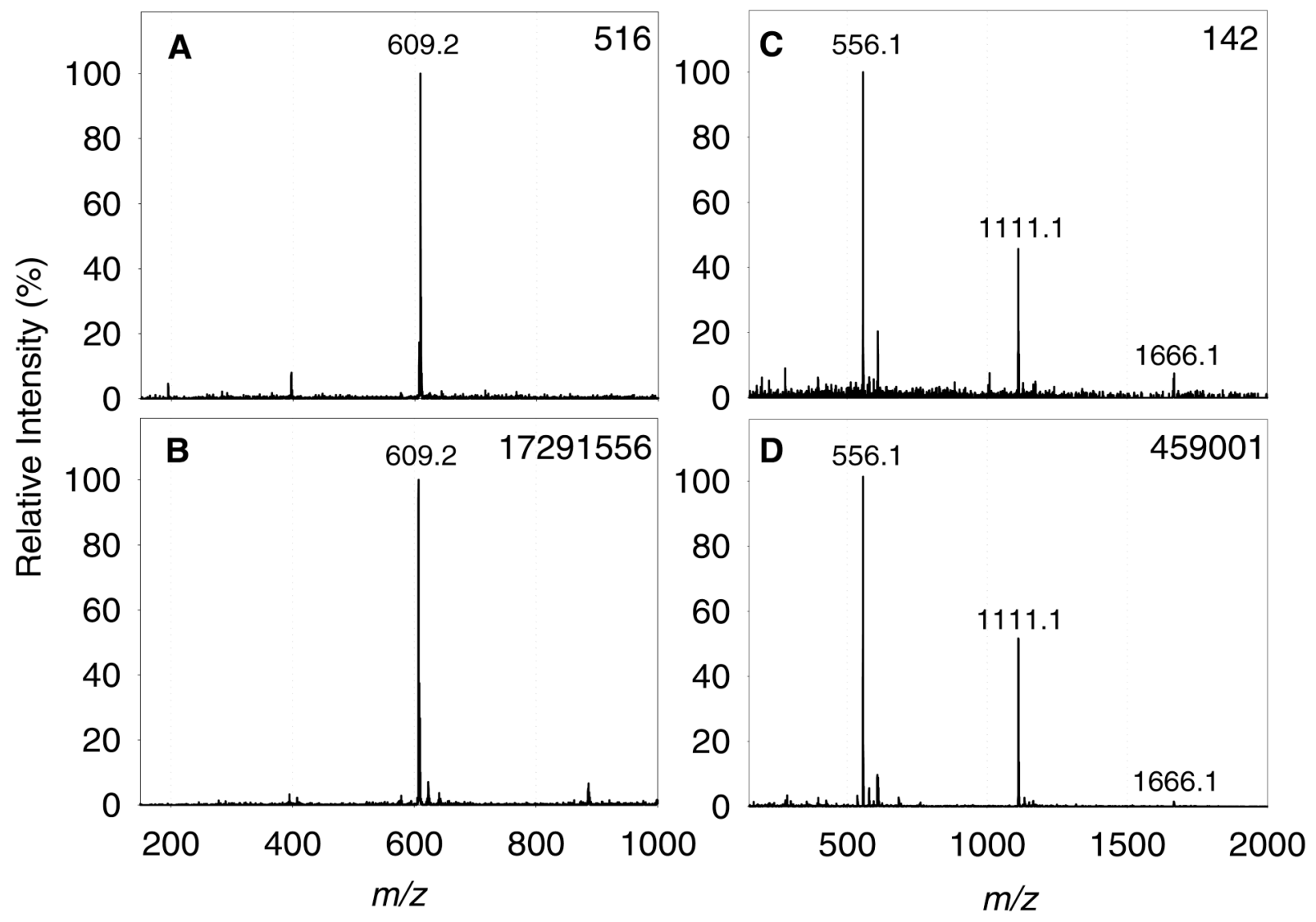

Figure 3.

AMUSE mass spectra produced by averaging $1.2 \mathrm{sec}$ of data obtained with different devices. (A) $5 \mu \mathrm{M}$ reserpine on a 5- $\mu \mathrm{m}$ chip, (B) $5 \mu \mathrm{M}$ reserpine on a 3- $\mu \mathrm{m}$ chip, (C) $10 \mu \mathrm{M}$ leucine enkephalin on a $5-\mu \mathrm{m}$ chip, and (D) $5 \mu \mathrm{M}$ leucine enkephalin on a $3-\mu \mathrm{m}$ chip. All solutions were prepared using 99.9:0.1 (v:v) water:glacial acetic acid as the solvent. Operating

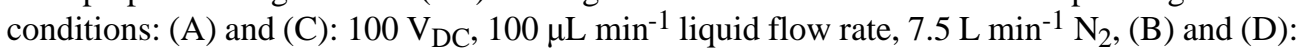
$100 \mathrm{~V}_{\mathrm{DC}}, 30 \mu \mathrm{L} \mathrm{min}{ }^{-1}$ liquid flow rate, $9.3 \mathrm{~L} \mathrm{~min}^{-1} \mathrm{~N}_{2}$. The base peak absolute intensity is noted in the upper right corner of each panel. 


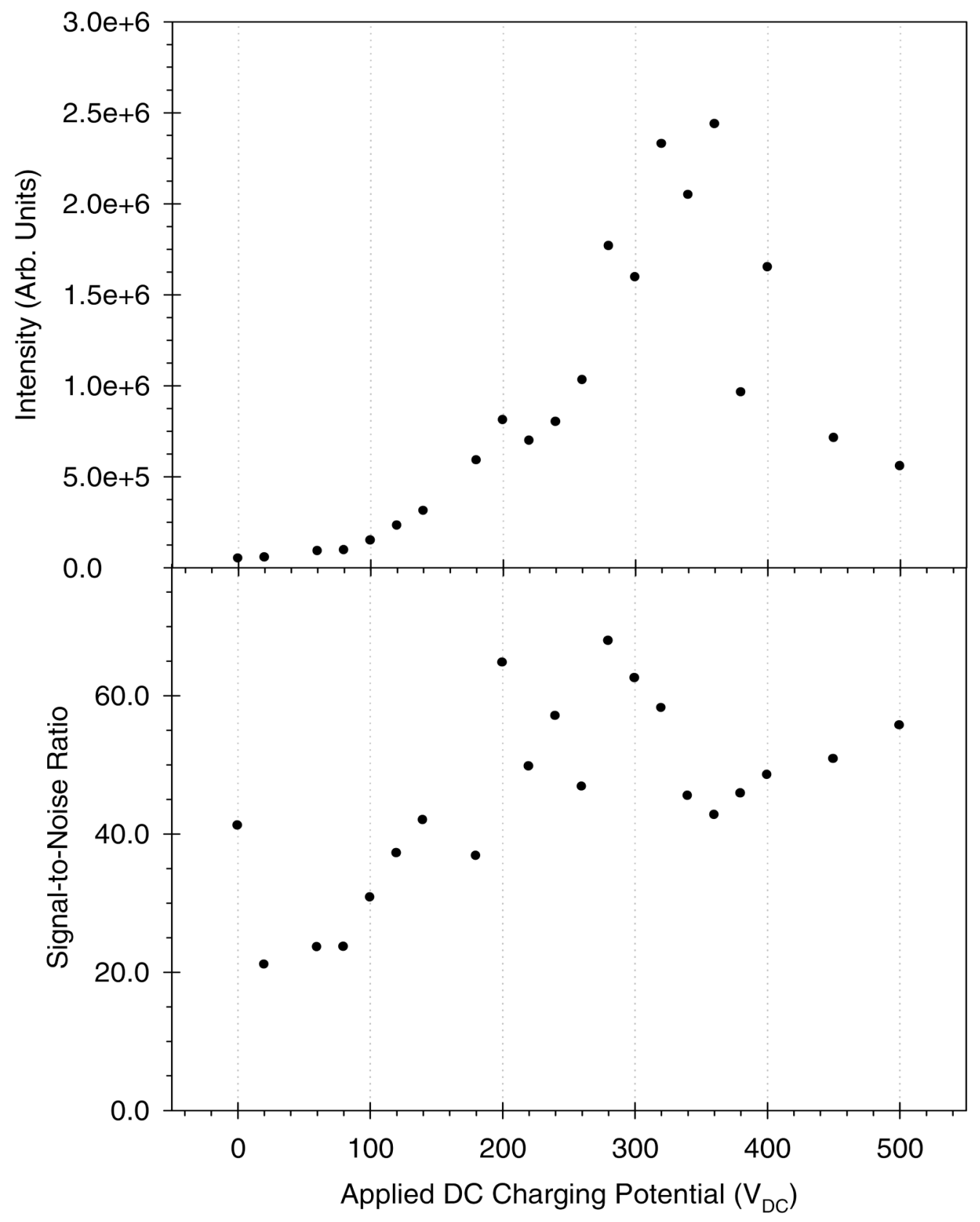

Figure 4.

Absolute intensity (top) and signal-to-noise ratio (bottom) for the leucine enkephalin [M $+\mathrm{H}]^{+}$ion vs. DC charging potential for a $1 \mu \mathrm{M}$ leucine enkephalin solution in 99.9:0.1 (v:v) water:acetic acid. An AMUSE chip with 3- $\mu$ m nozzles was used. Operating conditions: 40

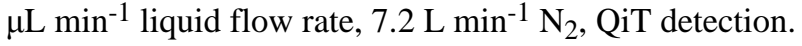



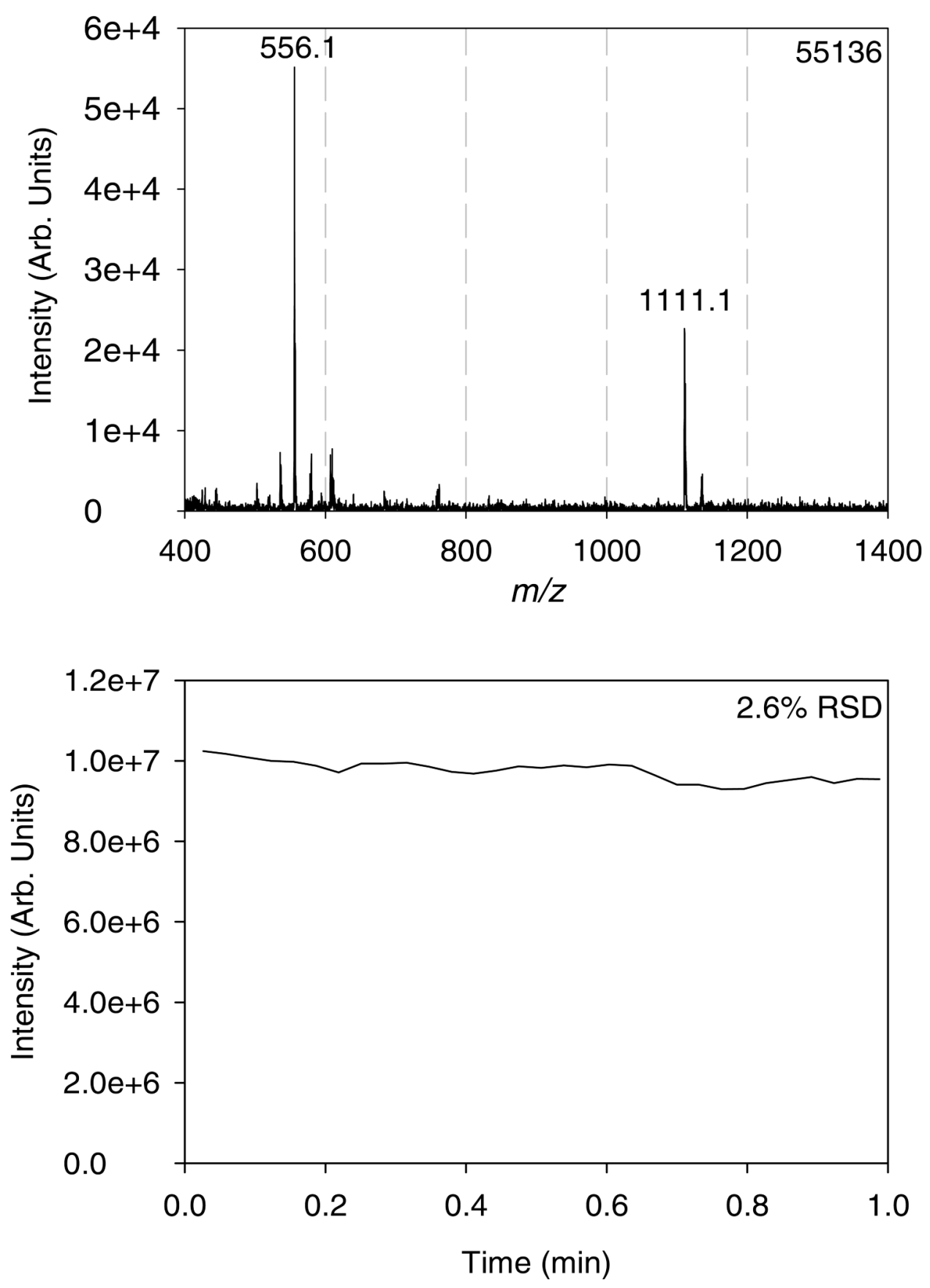

Figure 5.

Mass spectrum (top) and total ion trace (bottom) obtained for a $1 \mu \mathrm{M}$ leucine enkephalin solution in 99.9:0.1 (v:v) water:acetic acid in RF-only ionization mode ( $0 \mathrm{~V}_{\mathrm{DC}}$ charging potential). An AMUSE chip with 3- $\mu$ m nozzles was used. Operating conditions: $40 \mu \mathrm{L} \mathrm{min}{ }^{-1}$ liquid flow rate, 7.2 $\mathrm{L} \mathrm{min}^{-1} \mathrm{~N}_{2}$, QiT detection. 


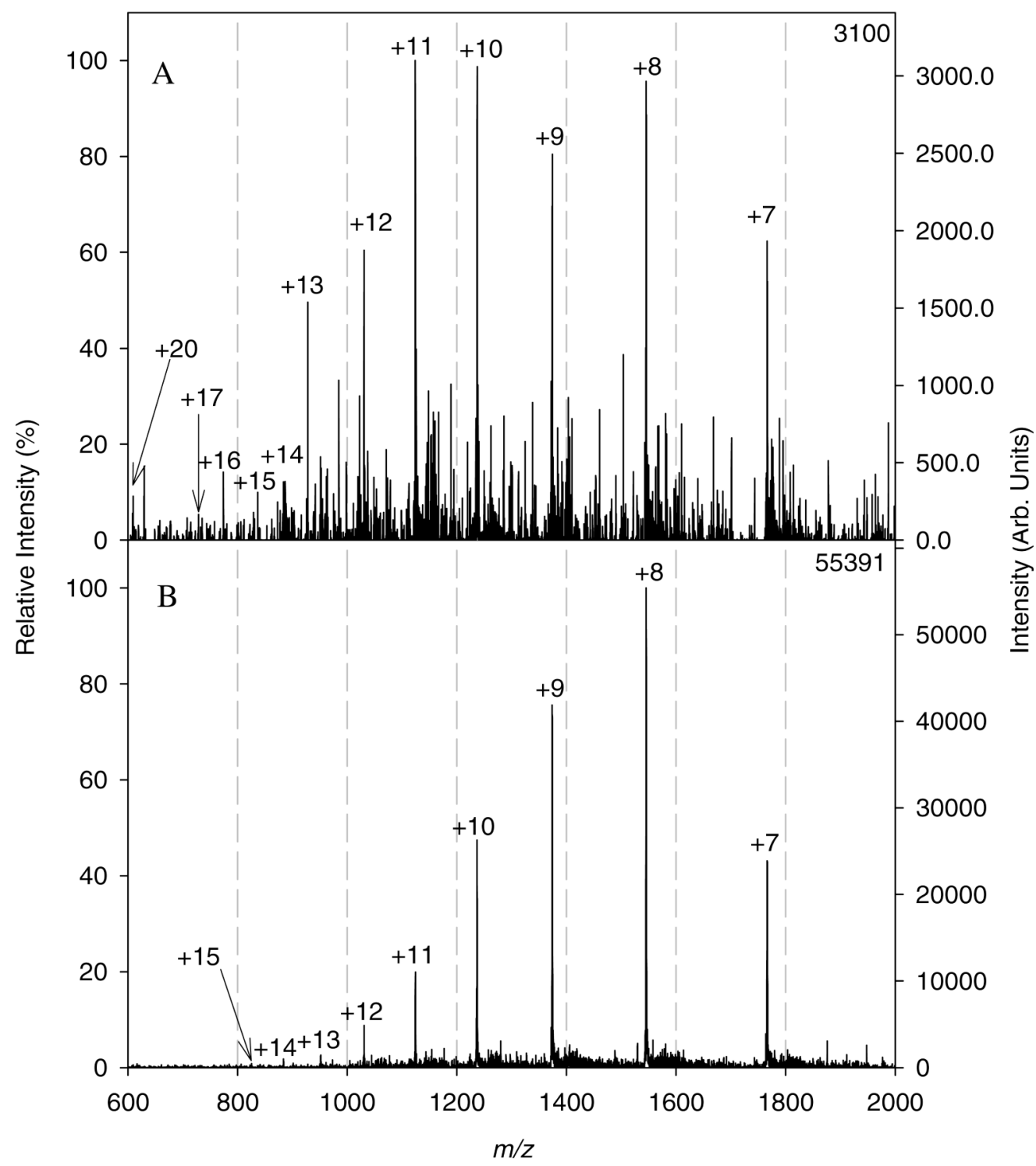

Figure 6.

Mass spectra of cytochrome $\mathrm{C}$ in 99.9:0.1 (v:v) water:acetic acid (240 pmol total, 2.4 pmol nozzle ${ }^{-1}$ ) obtained by AMUSE ionization from a chip with $3-\mu \mathrm{m}$ nozzles and using either (A) nitrogen at ambient temperature or (B) nitrogen heated to $40{ }^{\circ} \mathrm{C}$ to operate the Venturi device. Operating conditions: $60 \mu \mathrm{L} \mathrm{m^{-1 }}$ liquid flow rate, $100 \mathrm{~V}_{\mathrm{D}} \mathrm{C}, 8 \mathrm{~L} \mathrm{~min}^{-1}$, QiT detection. 